\title{
Hydrothermal synthesis, characterization and luminescent properties of lanthanide-doped $\mathrm{NaLaF}_{4}$ nanoparticles
}

\author{
JIGMET LADOL, HEENA KHAJURIA, SONIKA KHAJURIA and HAQ NAWAZ SHEIKH* \\ Department of Chemistry, University of Jammu, Jammu 180006, India
}

MS received 16 December 2015; accepted 2 February 2016

\begin{abstract}
Nanoparticles of sodium lanthanum (III) fluoride-doped and co-doped with $\mathrm{Eu}^{3+} / \mathrm{Tb}^{3+}$ were prepared by the hydrothermal method using citric acid as structure-directing agent. Structural aspects and optical properties of synthesized nanoparticles were studied by powder X-ray diffraction (XRPD), scanning electron microscopy (SEM), transmission electron microscopy (TEM), selected area electron diffraction (SAED), energy-dispersive X-ray spectra (EDS), particle size by dynamic light scattering (DLS), Fourier transform infrared (FTIR) spectrum and photoluminescence (PL) techniques. Nanoparticles consist of well-crystallized hexagonal phase and the average crystallite size for undoped and doped-NaLaF 4 nanoparticles are in the range of 20-22 nm. TEM images show that nanoparticles have cylindrical shape and crystalline nature of nanoparticles was confirmed by SAED patterns. Downconversion (DC) luminescent properties of doped $\mathrm{NaLaF}_{4}$ were also investigated and impact of co-doping has been explored.
\end{abstract}

Keywords. Citric acid; X-ray diffraction; down-conversion emission; energy transfer.

\section{Introduction}

Lanthanide-doped fluoride nanoparticles have attracted attention due to distinct optical, electrical and magnetic properties arising from $4 \mathrm{f}$ electronic configurations [1-3]. Among various host materials of lanthanide-doped fluoride nanoparticles, $\mathrm{AReF}_{4}(\mathrm{~A}=$ alkali metal; $\mathrm{Re}=$ rare-earth metal; $\mathrm{F}$ $=$ fluoride) exhibit some distinct advantages relative to other luminescent materials due to the low phonon energy, low non-radiative decay rates and high radiative emission rates [4,5]. These compounds doped with trivalent lanthanide ions possess prominent luminescent features such as high luminescence quantum yield, narrow bandwidth, long-lived emission and large Stokes shift [6,7]. These properties made them promising materials in numerous fields such as solid state lasers [8], multicolour three-dimensional displays [9], optical processing sensors [10], solar cells [11], biological labels and imaging [12]. Due to the concerns of toxicity and optical instability of quantum dots and organic dye molecules used as biomarkers for applications in immunoassay, cell imaging and photodynamic therapy (PDT), lanthanide-doped fluorescent nanoparticles have become promising alternative materials owing to their superior physical and chemical properties $[13,14]$. Sodium rare-earth fluorides exhibit two polymorphic forms in crystalline structure, namely, cubic and hexagonal phases, depending on the synthetic conditions and methods. Among all the investigated lanthanide-doped nanoscale hosts, the hexagonal phase sodium rare-earth fluorides are considered as the most excellent host lattices for photoluminescence (PL) since they normally have lower phonon

\footnotetext{
*Author for correspondence (hnsheikh@ rediffmail.com)
}

energy, which decreases the non-radiative relaxation probability and subsequently increases the luminescent efficiency [15-17]. The radius of rare-earth ions plays a key role in controlling crystal phase and shape. Sodium rare-earth fluoride hosts with large ionic radii, have high tendency to form hexagonal phase nanoparticles [18]. The crystal structure and size of the sodium rare-earth fluorides play important roles in controlling the optical properties [19-21]. These lanthanide-doped luminescent materials have been synthesized using various methods such as thermal decomposition [22], co-precipitation [23], hydro(solvo)thermal [24,25], ionic liquid-based synthesis [26], microemulsion-assisted [27] and microwave-assisted synthesis [28]. Among these methods, hydrothermal synthesis allows excellent control over particle size, shape, distribution and crystallinity of the material. Synthesis is conducted in a stainless autoclave using water as a solvent and nanoparticles formation occurs under high autogenous pressure at a synthetic temperature above the boiling point of solvent or mixed solution.

In this paper, $\mathrm{Tb}^{3+}, \mathrm{Eu}^{3+}$ and $\mathrm{Eu}^{3+} / \mathrm{Tb}^{3+}$ co-doped hexagonal phase $\mathrm{NaLaF}_{4}$ nanoparticles have been successfully synthesized by a facile hydrothermal method. Luminescent properties of dopant ion in hexagonal $\mathrm{NaLaF}_{4}$ nanoparticles have been investigated and discussed.

\section{Experimental}

\subsection{Materials and characterization techniques}

Europium(III) nitrate hexahydrate $\mathrm{Eu}\left(\mathrm{NO}_{3}\right)_{3} \cdot 6 \mathrm{H}_{2} \mathrm{O}(99.9 \%)$, terbium(III) nitrate hydrate $\mathrm{Tb}\left(\mathrm{NO}_{3}\right)_{3} \cdot \mathrm{H}_{2} \mathrm{O}(99.9 \%)$ and ammonium tetrafluoroborate $\mathrm{NH}_{4} \mathrm{BF}_{4}$ were purchased from 
Alfa Aesar and other chemicals such as citric acid, sodium hydroxide and ethanol were of analytical grade. All the chemicals were used as received without further purification. Deionized water was used throughout the process.

The phase structure and size of as-prepared samples were determined from powder X-ray diffraction (XRPD) using D8 X-ray diffractometer (Bruker) at a scanning rate of $12^{\circ} \mathrm{min}^{-1}$ in the $2 \theta$ range from 10 to $80^{\circ}$, with $\mathrm{CuK} \alpha$ radiation $(\lambda=0.15405 \mathrm{~nm})$. Transmission electron microscopy (TEM) and selected area electron diffraction (SAED) patterns were recorded on Tecnai $\mathrm{G}^{2} \mathrm{~S}$-twin transmission electron microscope with field emission gun operating at $200 \mathrm{kV}$. Samples for TEM measurements were prepared by evaporating a drop of colloid onto a carbon-coated copper grid. The energy spectra were obtained by energy-dispersive X-ray spectrum (EDS, Oxford Instrument) equipped on scanning electron microscope (SEM, Suprs55Zeiss). SEM provided extremely wide operating voltage range from 0.02 to $30 \mathrm{kV}$. The particle size of each compound was determined by dynamic light scattering (DLS) technique using Zetasizer Nano ZS-90 (Malvern Instruments Ltd, Worcestershire, UK). The infrared spectra were recorded on a Shimadzu Fourier transform infrared spectrometer (FTIR) over the range of wave number $4000-400 \mathrm{~cm}^{-1}$ and the standard $\mathrm{KBr}$ pellet technique was employed. The PL excitation and emission spectra were recorded at room temperature using Agilent Cary Eclipse Fluorescence Spectrophotometer equipped with a xenon lamp that was used as an excitation source. Radiative lifetime of luminescent nanospheres was calculated from decay curves using Picosecond Time-resolved Spectrometer, Eddinburg Instruments, Model: FSP920. All the measurements were performed at room temperature.

\subsection{Synthesis of undoped and doped-NaLaF ${ }_{4}$ nanoparticles}

The pure/undoped $\mathrm{NaLaF}_{4}$ and $\mathrm{Ln}^{3+}(\mathrm{Ln}=\mathrm{Tb}, \mathrm{Eu}$ and $\mathrm{Eu} / \mathrm{Tb}$ )-doped $\mathrm{NaLaF}_{4}$ nanoparticles were synthesized by a facile hydrothermal method using citric acid as the structure-directing agent. In typical synthesis of undoped $\mathrm{NaLaF}_{4}$ nanoparticles, aqueous solution $(3.5 \mathrm{ml})$ of $\mathrm{La}\left(\mathrm{NO}_{3}\right)_{3} \cdot 6 \mathrm{H}_{2} \mathrm{O}(0.5 \mathrm{mmol}, 0.22 \mathrm{~g})$ was mixed with aqueous solution $(5 \mathrm{ml})$ of citric acid $(0.5 \mathrm{mmol}, 0.1 \mathrm{~g})$ and $\mathrm{NaOH}(0.3 \mathrm{~g})$, while stirring thoroughly. To this reaction mixture, $5 \mathrm{ml}$ of ethanol was added. Then, $1 \mathrm{ml}$ aqueous solution of $\mathrm{NH}_{4} \mathrm{BF}_{4}(2 \mathrm{mmol}, 0.20 \mathrm{~g})$ was added dropwise to the mixture. After vigorous stirring at room temperature for about $30 \mathrm{~min}$, colloidal solution was transferred into a $23 \mathrm{ml}$ Teflon-lined autoclave, sealed and heated at $180^{\circ} \mathrm{C}$ for $18 \mathrm{~h}$. To synthesize $\mathrm{NaLa}_{0.80} \mathrm{~Tb}_{0.20} \mathrm{~F}_{4}$ nanoparticles, aqueous solution $(3.5 \mathrm{ml})$ of $\mathrm{La}\left(\mathrm{NO}_{3}\right)_{3} \cdot 6 \mathrm{H}_{2} \mathrm{O}(0.4 \mathrm{mmol}, 0.173 \mathrm{~g})$ and $\mathrm{Tb}\left(\mathrm{NO}_{3}\right)_{3} \cdot \mathrm{H}_{2} \mathrm{O}(0.1 \mathrm{mmol}, 0.04 \mathrm{~g})$ was mixed with aqueous solution $(5 \mathrm{ml})$ of citric acid $(0.5 \mathrm{mmol}, 0.1 \mathrm{~g})$ and $\mathrm{NaOH}$ $(0.3 \mathrm{~g})$, while stirring thoroughly. All reaction conditions and procedures adopted were same as above. As autoclave was cooled to room temperature naturally, the precipitates were separated by centrifugation, washed with deionized water and ethanol in sequence, and then collected nanoparticles were dried at $60^{\circ} \mathrm{C}$ for $12 \mathrm{~h}$. Similar procedure and reaction condition were used for the synthesis of $\mathrm{NaLa}_{0.80} \mathrm{Eu}_{0.20} \mathrm{~F}_{4}$ and $\mathrm{NaLa}_{0.80} \mathrm{Eu}_{0.10} \mathrm{~Tb}_{0.10} \mathrm{~F}_{4}$ nanoparticles.

\section{Results and discussion}

\subsection{XRPD measurements}

Figure 1 shows the XRPD patterns of undoped $\mathrm{NaLaF}_{4}$ and doped-NaLaF $4: \mathrm{Tb}^{3+}, \mathrm{NaLaF}_{4}: \mathrm{Eu}^{3+}, \mathrm{NaLaF}_{4}: \mathrm{Eu}^{3+} / \mathrm{Tb}^{3+}$ nanoparticles. The crystallinity of these nanoparticles is confirmed by their highly intense X-ray reflections in their corresponding XRPD patterns. In all the cases, width of the diffraction lines is broad which indicates that the size of synthesized $\mathrm{NaLaF}_{4}$ nanoparticles is in nanoscale. The XRPD patterns of the nanoparticles show that the peak positions and intensities agree well with the literature values in the JCPDS standard card (no. 50-0155) for hexagonal phase $\mathrm{NaLaF}_{4}$ nanoparticles. Moreover, no other phase was detected, revealing high purity of samples. Similar patterns of rare-earth-doped $\mathrm{NaLaF}_{4}$ nanoparticles indicate that rare

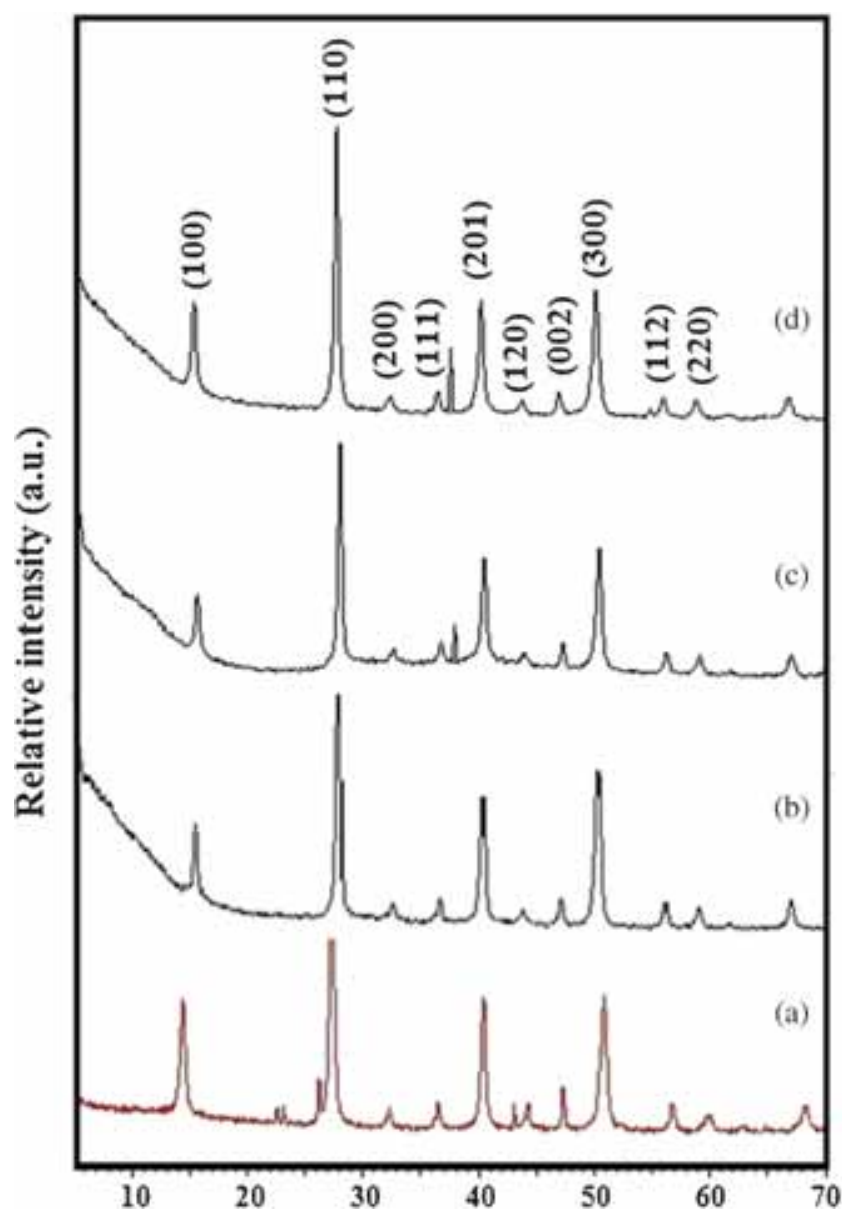

Figure 1. XRPD spectra of (a) undoped $\mathrm{NaLaF}_{4}$, (b) doped $\mathrm{NaLaF}_{4}: \mathrm{Tb}^{3+}$, (c) $\mathrm{NaLaF}_{4}: \mathrm{Eu}^{3+}$ and (d) $\mathrm{NaLaF}_{4}: \mathrm{Eu}^{3+} / \mathrm{Tb}^{3+}$ nanoparticles. 
earth dopants are occupying $\mathrm{La}^{3+}$ site in the lattice and single phase products are obtained even on doping. The hexagonal $\mathrm{NaLaF}_{4}$ phase showing diffraction peaks at 16.6, 28.9, 33.6, 37.7, 41.4, 44.9, 48.1, 51.3, 57.2 and $60.0^{\circ}$ can be indexed to the planes (100), (110), (200), (111), (201), (120), (002), (300), (112) and (220), respectively. Major peaks were used to calculate the average crystallite size of these nanoparticles according to Scherrer's equation

$$
D=K \lambda / \beta \cos \theta,
$$

where $D$ is the crystallite size, $\lambda$ the wavelength of the $\mathrm{CuK} \alpha$ radiant, $\lambda=0.15405 \mathrm{~nm}, \beta$ the FWHM (full-width at half-maximum) of diffraction peaks, $\theta$ the diffraction angle and $K$ the Scherrer constant equals to 0.89 . The calculated average crystallite size of nanoparticles lies in the range of 20-22 $\mathrm{nm}$. Slight variation in particle size is due to dopant ions which cause negligible change in FWHM values. The enhanced intensity of peaks indicates preferential crystal growth in this direction. The average diameters of the three samples calculated by XRPD data and analysed by the DLS technique are summarized in table 1 . Various other parameters (table 1) such as interplanar spacing ( $d$ in $\AA$ ), microstrain $(\varepsilon)$, dislocation density ( $\rho$ in $10^{15} \mathrm{~m} \mathrm{~m}^{-3}$ ) and distortion parameter $(g)$ along (110) plane were calculated using the following equations:

$$
\begin{aligned}
& d=\lambda / 2 \sin \theta ; \varepsilon=\beta \cos \theta / 4 ; \rho=1 / D^{2}(D \text { in } \AA) \\
& \text { and } g=\beta / \tan \theta .
\end{aligned}
$$

It is clear from the table that microstrain value decreases with increase in the crystallite size [29].

\subsection{SEM, TEM and EDS analyses}

The surface morphology of the undoped and doped-NaLaF 4 nanoparticles was explored from SEMs. SEM images of nanoparticles at different magnifications show hexagonalshaped $\mathrm{NaLaF}_{4}$ nanostructures (figure 2). Compositional analysis by EDS (figure 3) reveals incorporation of $\mathrm{Ln}^{3+}$ $(\mathrm{Ln}=\mathrm{Tb}, \mathrm{Eu}$ and $\mathrm{Eu} / \mathrm{Tb})$ ions in host $\mathrm{NaLaF}_{4}$ nanoparticles.

\begin{tabular}{|c|c|c|c|c|c|c|c|c|}
\hline \multirow[b]{2}{*}{ Samples } & \multirow{2}{*}{$\begin{array}{c}\text { Peak position, } 2 \theta \\
\text { (degree) }\end{array}$} & \multicolumn{2}{|c|}{ Particle size, $D(\mathrm{~nm})$} & \multicolumn{2}{|c|}{$d$-Value $(\AA)$} & \multirow[b]{2}{*}{ Micro-strain, $\varepsilon$} & \multirow{2}{*}{$\begin{array}{l}\text { Dislocation density, } \\
\rho\left(10^{15} \mathrm{~m} \mathrm{~m}^{-3}\right)\end{array}$} & \multirow{2}{*}{$\begin{array}{c}\text { Distortion } \\
\text { parameter, } g\end{array}$} \\
\hline & & PXRD & DLS & Observed & Calculated & & & \\
\hline $\mathrm{NaLaF}_{4}$ & 29.006 & 20.19 & 24.0 & 3.078 & 3.074 & 0.0972 & 2.453 & 1.552 \\
\hline $\mathrm{NaLaF}_{4}: \mathrm{Tb}^{3+}$ & 28.996 & 21.90 & 49.9 & 3.059 & 3.058 & 0.0895 & 2.085 & 1.431 \\
\hline $\mathrm{NaLaF}_{4}: \mathrm{Eu}^{3+}$ & 29.003 & 20.79 & 48.6 & 3.047 & 3.046 & 0.0944 & 2.314 & 1.508 \\
\hline $\mathrm{NaLaF}_{4}: \mathrm{Eu}^{3+} / \mathrm{Tb}^{3+}$ & 29.024 & 21.24 & 81.2 & 3.072 & 3.074 & 0.0919 & 2.217 & 1.468 \\
\hline
\end{tabular}
Magnesium is present as impurity in figure $3 \mathrm{a}$.

Table 1. Evaluated parameters from XRPD data and DLS analysis for undoped and doped $\mathrm{NaLaF}_{4}$ nanoparticles.
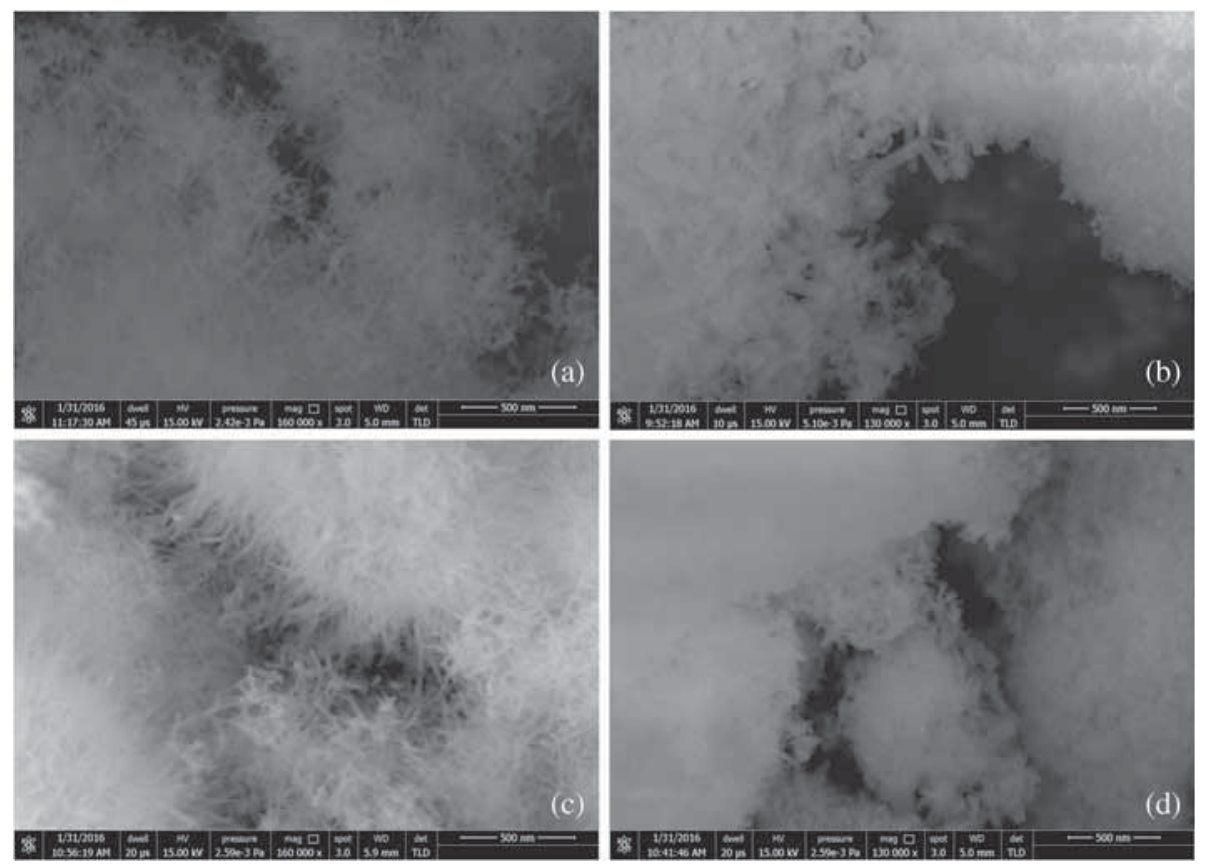

Figure 2. $\mathrm{SEM}$ images of (a) undoped $\mathrm{NaLaF}_{4}$, (b) doped $\mathrm{NaLaF}_{4}: \mathrm{Tb}^{3+}$, (c) $\mathrm{NaLaF}_{4}: \mathrm{Eu}^{3+}$ and (d) $\mathrm{NaLaF}_{4}: \mathrm{Eu}^{3+} / \mathrm{Tb}^{3+}$ nanoparticles. 


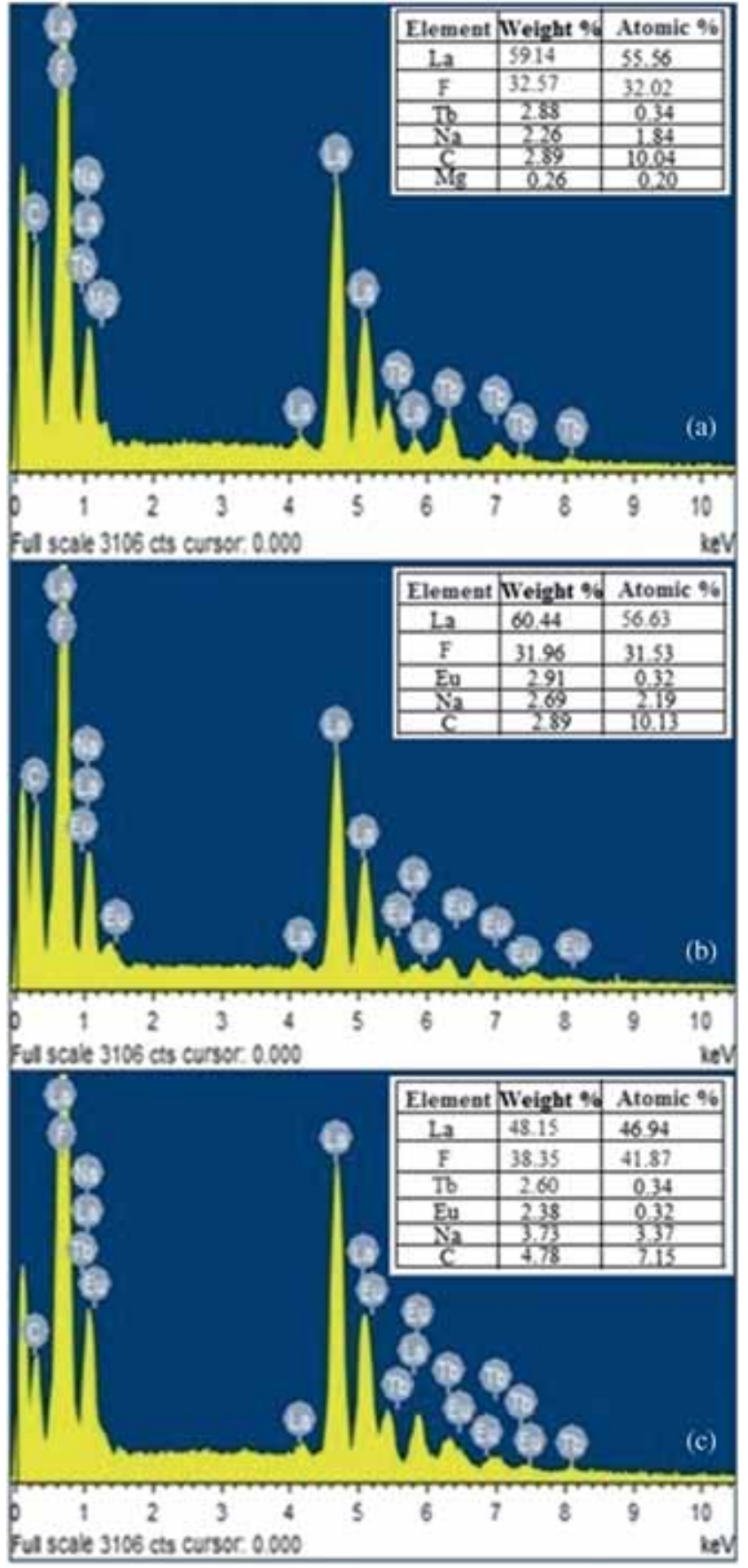

Figure 3. EDS spectra of (a) $\mathrm{NaLaF}_{4}: \mathrm{Tb}^{3+}$, (b) $\mathrm{NaLaF}_{4}: \mathrm{Eu}^{3+}$ and (c) $\mathrm{NaLaF}_{4}: \mathrm{Eu}^{3+} / \mathrm{Tb}^{3+}$ nanoparticles.

Figure 4 shows TEM images and SAED patterns of undoped and doped-NaLaF 4 nanoparticles. The images show well-dispersed particles cylindrical-shaped morphology at different magnifications. The SAED patterns show that these nanoparticles are well crystalline in nature. High crystallinity is important for phosphors because high crystallinity generally means fewer traps and stronger UC and DC luminescences.

\subsection{Formation mechanism of nanoparticles}

On the basis of the above analysis, growth of nanoparticles of lanthanum fluorides takes place through a series of chemical transformations under the influence of surfactant. It is known that citric acid can be adsorbed strongly on metal and mineral surfaces and significantly alters the surface properties and mineral growth behaviour [30]. Here, citric acid may play a crucial role in the formation of undoped and dopedsubmicron rods. First, the rare-earth ions react with citrate groups in solution to form the rare-earth citrate complex, equation (1). Then, in aqueous solution, $\mathrm{NH}_{4} \mathrm{BF}_{4}$ is hydrolysed to produce $\mathrm{BO}_{3}^{3-}$ and $\mathrm{F}^{-}$anions, as shown in equation (2). Sodium hydroxide in presence of acidic medium produces $\mathrm{Na}^{+}$ion and water molecule, equation (3). $\mathrm{La}^{3+}$ cit complex then reacts with $\mathrm{F}^{-}$ion produced during slow hydrolysis of $\mathrm{NH}_{4} \mathrm{BF}_{4}$ to form $\mathrm{NaLaF}_{4}$ nuclei as presented in equation (4). The probable reaction processes for the formation of $\mathrm{NaLaF}_{4}$ can be summarized as

$$
\begin{aligned}
& \mathrm{La}^{3+}+\text { citrate } \rightarrow \mathrm{La}^{3+}-\text { cit, } \\
& \mathrm{BF}_{4}^{-}+3 \mathrm{H}_{2} \mathrm{O} \rightarrow 3 \mathrm{HF}+\mathrm{F}^{-}+\mathrm{H}_{3} \mathrm{BO}_{3}, \\
& \mathrm{NaOH}+\mathrm{H}^{+} \rightarrow \mathrm{Na}^{+}+\mathrm{H}_{2} \mathrm{O}, \\
& \left(\mathrm{La}^{3+}-\text { cit }\right)+4 \mathrm{~F}^{-}+\mathrm{Na}^{+} \rightarrow \mathrm{NaLaF}_{4}-\text { cit. }
\end{aligned}
$$

At this stage, the nucleation rate of $\mathrm{NaLaF}_{4}: \mathrm{Tb}^{3+}$, $\mathrm{NaLaF}_{4}: \mathrm{Eu}^{3+}$ and $\mathrm{NaLaF}_{4}: \mathrm{Eu}^{3+} / \mathrm{Tb}^{3+}$ nanoparticles is strongly affected by the incorporation of $\mathrm{F}^{-}$ions into the rare-earth complex [31]. Finally, citrate groups selectively bind to certain crystal surfaces of the nanoparticles, probably providing driving force (electrostatic, hydrogen, coordination bonds, etc.) that makes primary particles assemble into polydispersed submicron rods [32-34].

\subsection{Particle size by $D L S$}

Figure 5 shows the particle size distribution curves for synthesized $\mathrm{Ln}^{3+}$-doped and undoped $\mathrm{NaLaF}_{4}$ nanoparticles determined by DLS. Before DLS analysis, the nanoparticles were uniformly dispersed in deionized water by mild sonication for $5 \mathrm{~min}$. The approximate sizes of undoped and doped-NaLaF $\mathrm{N}_{4}$ nanoparticles were found in the range of 24-81 nm. It was observed that doped-NaLaF $\mathrm{N}_{4}$ nanoparticles have larger size when compared to undoped-NaLaF 4 nanoparticles. Undoped $\mathrm{NaLaF}_{4}, \mathrm{La}^{3+}$ has larger ionic radius and large surface electron charge density that hinder the diffusion of $\mathrm{F}^{-}$ions needed for crystal growth as a result of charge repulsion, consequently resulting in retardation of nanocrystal growth [35]. And in case of doped $\mathrm{NaLaF}_{4}$, where $\mathrm{La}^{3+}$ is substituted by dopant ion with smaller ionic radius, increase in size of nanoparticles is attributed to the same reasons. It can be seen that the sizes of the particles analysed using DLS technique are larger than those calculated from the XRPD measurement. This might be due to the surface 

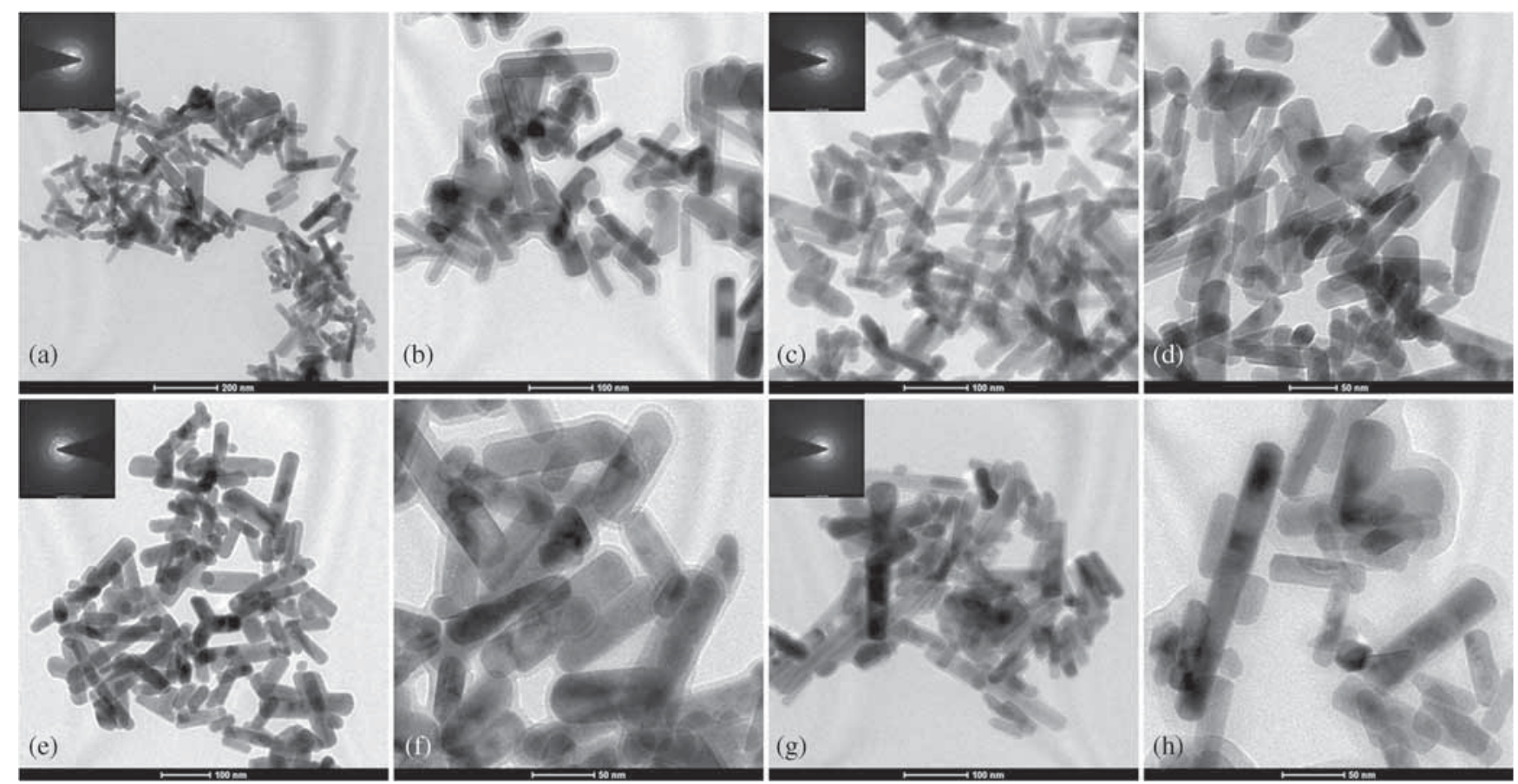

Figure 4. TEM images of $(\mathbf{a}, \mathbf{b})$ undoped $\mathrm{NaLaF}_{4} ;(\mathbf{c}, \mathbf{d})$ doped $\mathrm{NaLaF}_{4}: \mathrm{Tb}^{3+} ;(\mathbf{e}, \mathbf{f}) \mathrm{NaLaF}_{4}: \mathrm{Eu}^{3+}$ and $(\mathbf{g}, \mathbf{h}) \mathrm{NaLaF}_{4}: \mathrm{Eu}^{3+} / \mathrm{Tb}^{3+}$ nanoparticles. Insets in $\mathbf{a}, \mathbf{c}, \mathbf{e}$ and $\mathbf{g}$ are SAED patterns.

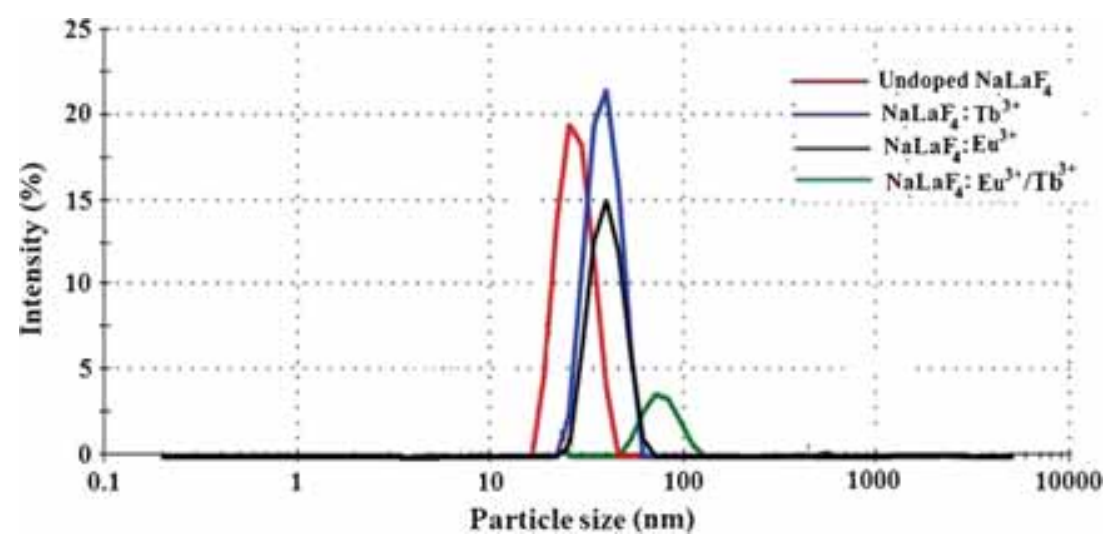

Figure 5. Particle size by DLS for undoped $\mathrm{NaLaF}_{4}$, doped $\mathrm{NaLaF}_{4}: \mathrm{Tb}^{3+}, \mathrm{NaLaF}_{4}$ $: \mathrm{Eu}^{3+}$ and $\mathrm{NaLaF}_{4}: \mathrm{Eu}^{3+} / \mathrm{Tb}^{3+}$ nanoparticles.

solvation and agglomeration/aggregation of the particles in the colloidal solution.

\subsection{FTIR spectra}

The presence of citrate ligands at the surface of $\mathrm{NaLaF}_{4}$ : $\mathrm{Tb}^{3+}, \mathrm{NaLaF}_{4}: \mathrm{Eu}^{3+}$ and $\mathrm{NaLaF}_{4}: \mathrm{Eu}^{3+} / \mathrm{Tb}^{3+}$ nanoparticles can be proved by FTIR. Figure 6 shows the FTIR spectrum of as-prepared submicron rods. The broad band at $3451 \mathrm{~cm}^{-1}$ can be attributed to the stretching mode of hydrogen-bonded hydroxyl groups. The asymmetrical and symmetrical stretching vibration modes of $\mathrm{CH}_{2}$ group appear around 2908 and $2834 \mathrm{~cm}^{-1}$, respectively. The bands at
1686 and $1384 \mathrm{~cm}^{-1}$ can be assigned to the asymmetric and symmetric stretching vibrations of the carboxylic group $(-\mathrm{COOH})$ in the coated-citric acid, respectively.

\subsection{Luminescence properties}

One of the most remarkable features of lanthanide compounds is PL. The lanthanide ions have electronic configuration (Xe) $4 \mathrm{f}^{n}(n=0-14)$ that generates abundant electronic levels. Luminescence of lanthanide ions essentially originates from transitions of partially filled $4 \mathrm{f}$ electrons $[36,37]$. Since $4 \mathrm{f}$ orbitals are shielded by filled $5 \mathrm{~s}^{2} 5 \mathrm{p}^{6}$ sub-shells, the emission bands remain narrow even at room temperature. 


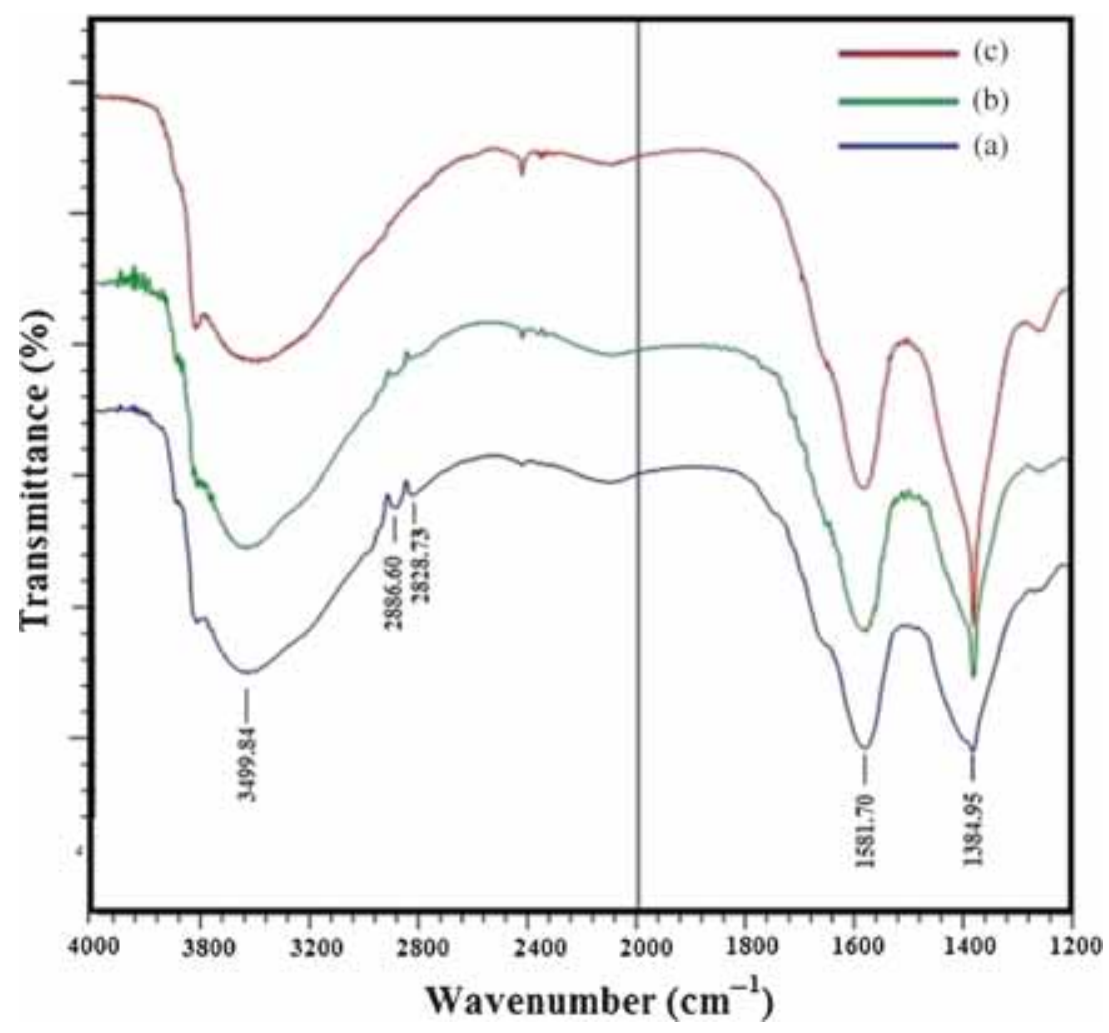

Figure 6. FTIR spectra of (a) $\mathrm{NaLaF}_{4}: \mathrm{Tb}^{3+}$, (b) $\mathrm{NaLaF}_{4}: \mathrm{Eu}^{3+}$ and (c) $\mathrm{NaLaF}_{4}$ : $\mathrm{Eu}^{3+} / \mathrm{Tb}^{3+}$ nanoparticles.

As a consequence of this, lanthanide-doped nanoparticles are able to emit light that covers ultraviolet (UV)-Visible to near infrared (NIR) regions. Our experimental results and previous investigations reveal that $\mathrm{NaLaF}_{4}$ is a promising host lattice for doping optically active lanthanide ions [38]. Accordingly, it was mainly focussed on down-conversion luminescent properties of $\mathrm{Ln}^{3+}(\mathrm{Ln}=\mathrm{Tb}, \mathrm{Eu}$ and $\mathrm{Eu} / \mathrm{Tb})$ doped $\mathrm{NaLaF}_{4}$ nanoparticles. $\mathrm{Eu}^{3+}$ and $\mathrm{Tb}^{3+}$ were chosen as dopant ions as these metal ions are highly luminescent with relatively long lifetimes [39]. 3.6a $\mathrm{NaLaF}_{4}: \mathrm{Tb}^{3+}$ : Figure 7 shows the solid-state excitation and emission spectra for the $\mathrm{NaLaF}_{4}: 20 \% \mathrm{~Tb}^{3+}$ sample. The excitation spectrum (black line) is composed of characteristic $\mathrm{f}-\mathrm{f}$ transition lines within the $\mathrm{Tb}$ ff configuration, which can be assigned to the transitions from the ${ }^{7} \mathrm{~F}_{6}$ ground state to the different excited states of $\mathrm{Tb}^{3+}$, i.e., $283 \mathrm{~nm}\left({ }^{5} \mathrm{I}_{6}\right)$, $303 \mathrm{~nm}\left({ }^{5} \mathrm{H}_{6}\right), 318 \mathrm{~nm}\left({ }^{5} \mathrm{D}_{0}\right), 339 \mathrm{~nm}\left({ }^{5} \mathrm{G}_{2}\right), 351 \mathrm{~nm}\left({ }^{5} \mathrm{D}_{2}\right)$ and $368 \mathrm{~nm}\left({ }^{5} \mathrm{G}_{6}\right)$. Upon excitation at 351 or $377 \mathrm{~nm}$, the obtained emission spectrum consists of four obvious lines centred at 490, 545, 585 and $621 \mathrm{~nm}$ originating from the

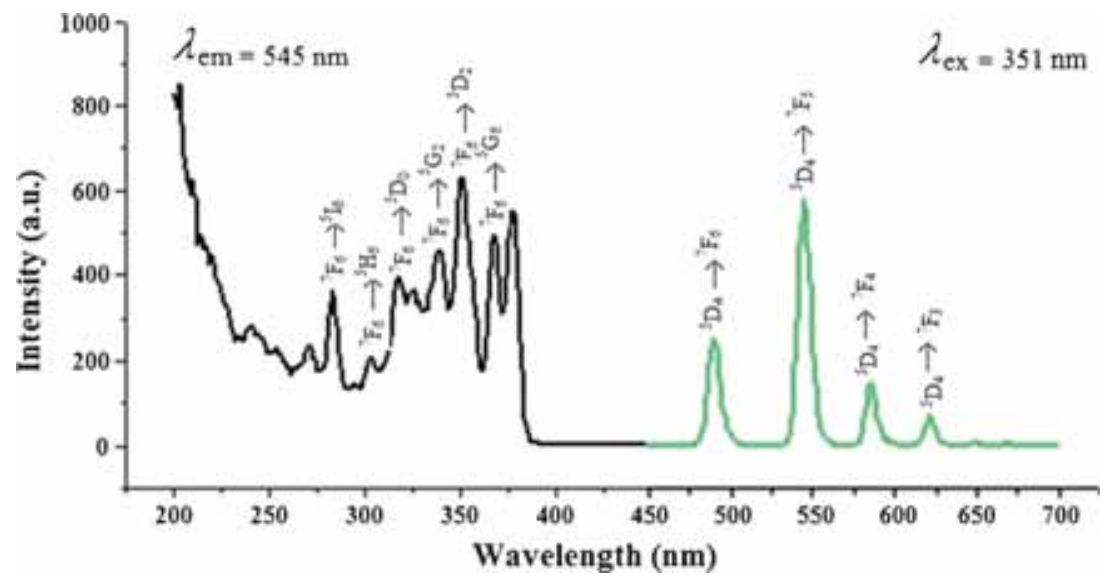

Figure 7. (Colour online) Excitation (black lines) and emission spectra (green lines) of $\mathrm{NaLaF}_{4}: 20 \% \mathrm{~Tb}^{3+}$ nanoparticles. 


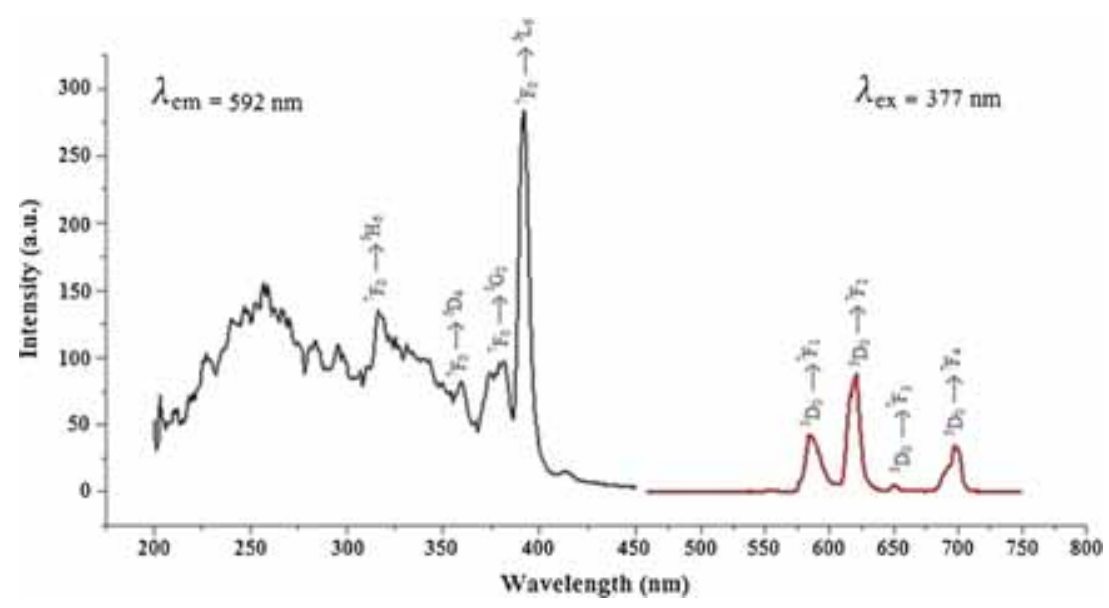

Figure 8. (Colour online) Excitation (black lines) and emission spectra (red lines) of $\mathrm{NaLaF}_{4}: 20 \% \mathrm{Eu}^{3+}$ nanoparticles.

transitions from the ${ }^{5} \mathrm{D}_{4}$ excited state to the ${ }^{7} \mathrm{~F}_{J}(J=6,5$, $4,3)$ ground states of the $\mathrm{Tb}^{3+}$ ions. The transition at $545 \mathrm{~nm}$, i.e., ${ }^{5} \mathrm{D}_{4} \rightarrow{ }^{7} \mathrm{~F}_{5}$ is most intense peak as it corresponds to transition, i.e., both magnetic dipole and electric-dipole allowed [40].

3.6b $\mathrm{NaLaF}_{4}: \mathrm{Eu}^{3+}$ : The excitation and emission spectra for $\mathrm{NaLaF}_{4}: 20 \% \mathrm{Eu}^{3+}$ sample are shown in figure 8. The excitation spectrum (black line) consists of several characteristic excitation lines of $\mathrm{Eu}^{3+}$ originating from its $4 \mathrm{f}^{6}$ configuration, which can be clearly assigned as $317 \mathrm{~nm}:{ }^{7} \mathrm{~F}_{0} \rightarrow{ }^{5} \mathrm{H}_{6}$; $361 \mathrm{~nm}:{ }^{7} \mathrm{~F}_{0} \rightarrow{ }^{5} \mathrm{D}_{4} ; 377 \mathrm{~nm}:{ }^{7} \mathrm{~F}_{0} \rightarrow{ }^{5} \mathrm{G}_{2}$; and $393 \mathrm{~nm}:$ ${ }^{7} \mathrm{~F}_{0} \rightarrow{ }^{5} \mathrm{~L}_{6}$. Upon excitation at $377 \mathrm{~nm}$, the corresponding emission spectrum comprises emission lines assigned at 592 $\mathrm{nm}:{ }^{5} \mathrm{D}_{0} \rightarrow{ }^{7} \mathrm{~F}_{1} ; 615 \mathrm{~nm}:{ }^{5} \mathrm{D}_{0} \rightarrow{ }^{7} \mathrm{~F}_{2} ; 650 \mathrm{~nm}:{ }^{5} \mathrm{D}_{0} \rightarrow{ }^{7} \mathrm{~F}_{3}$ and $695 \mathrm{~nm}:{ }^{5} \mathrm{D}_{0} \rightarrow{ }^{7} \mathrm{~F}_{4}$. Experimental data on photophysical properties of a number of $\mathrm{Eu}^{3+}$ ions established that the emission band centred around $592 \mathrm{~nm}$ corresponding to the ${ }^{5} \mathrm{D}_{0} \rightarrow{ }^{7} \mathrm{~F}_{1}$ transition is magnetic dipole in character, whereas the emission band centred around 615 and $695 \mathrm{~nm}$ corresponding to the ${ }^{5} \mathrm{D}_{0} \rightarrow{ }^{7} \mathrm{~F}_{2},{ }^{5} \mathrm{D}_{0} \rightarrow{ }^{7} \mathrm{~F}_{4}$ transitions, respectively, are electric dipole in character [41]. The transitions to the ${ }^{7} \mathrm{~F}_{0,3,5}$ levels are forbidden both in magnetic and electric dipole schemes and are usually very weak in the emission spectrum. The emission spectrum of $\mathrm{Eu}^{3+}$ ion is strongly influenced by the symmetry of the environment. If $\mathrm{Eu}^{3+}$ occupies a crystal site with inversion symmetry, the electric dipole transitions are strictly forbidden and ${ }^{5} \mathrm{D}_{0} \rightarrow{ }^{7} \mathrm{~F}_{1}$ is usually the dominant emission line. If there is no inversion symmetry at the $\mathrm{Eu}^{3+}$ site, the strength of the electric dipole transitions is higher. The ${ }^{5} \mathrm{D}_{0} \rightarrow{ }^{7} \mathrm{~F}_{2}$ transition is usually the strongest emission line in this case, because transitions with $\Delta J= \pm 2, \pm 4$ are hypersensitive to small deviations from inversion symmetry [42].

3.6c $\mathrm{NaLaF}_{4}: \mathrm{Eu}^{3+} / \mathrm{Tb}^{3+}$ : Figure 9a and b shows the excitation and emission spectra for co-doped $\left(10 \% \mathrm{Eu}^{3+}\right.$ and $\left.10 \% \mathrm{~Tb}^{3+}\right) \mathrm{NaLaF}_{4}$ nanoparticles. The excitation spectrum consists of characteristic $\mathrm{f}-\mathrm{f}$ transition lines of both $\mathrm{Tb}^{3+}$ and $\mathrm{Eu}^{3+}$ ions which can be clearly assigned as $317 \mathrm{~nm}$ :
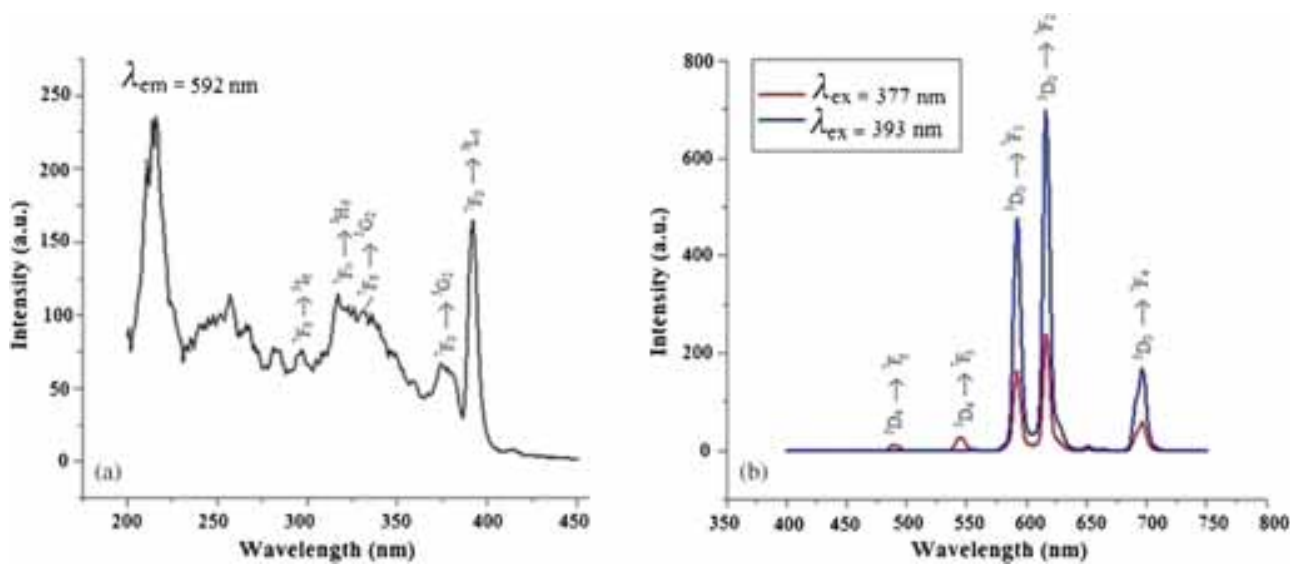

Figure 9. (a) Excitation and (b) emission spectra of $\mathrm{NaLaF}_{4}: 10 \% \mathrm{Eu}^{3+} / \mathrm{Tb}^{3+}$ nanoparticles monitored at 377 and $393 \mathrm{~nm}$, respectively. 

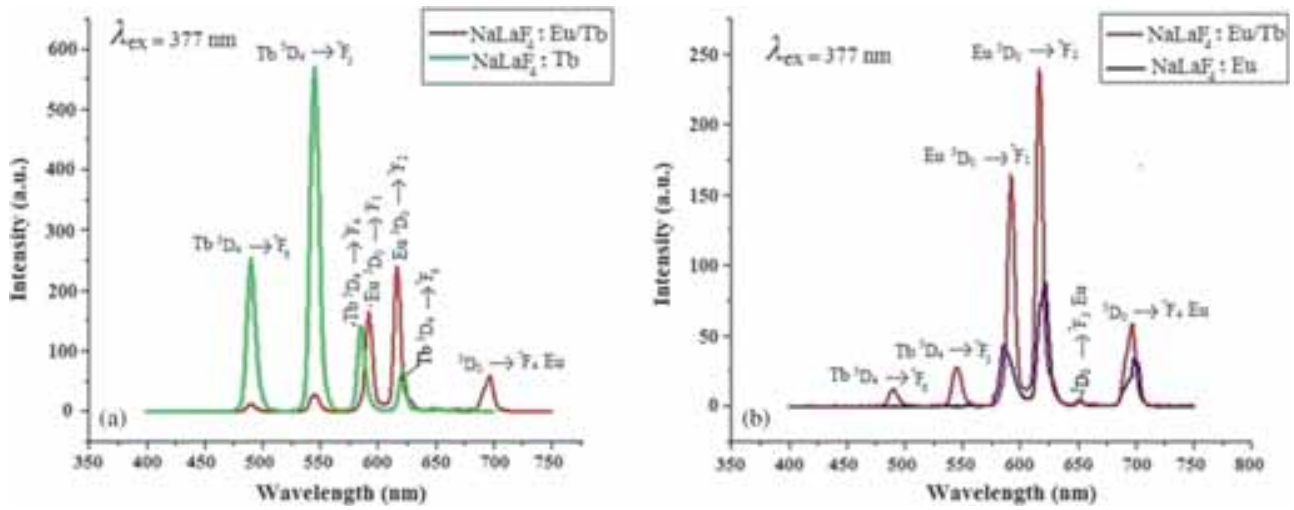

Figure 10. Emission spectra of (a) $\mathrm{Tb}^{3+}$ and $\mathrm{Eu}^{3+} / \mathrm{Tb}^{3+}$ co-doped $\mathrm{NaLaF}_{4}$ nanoparticles and (b) $\mathrm{Eu}^{3+}$ and $\mathrm{Eu}^{3+} / \mathrm{Tb}^{3+}$ co-doped $\mathrm{NaLaF}_{4}$ nanoparticles monitored at $377 \mathrm{~nm}$. Here, the decreased ${ }^{5} \mathrm{D}_{4}$ to ${ }^{7} \mathrm{~F}_{6,5}$ transitions in $\mathrm{Tb}$ as well as the increase in Eu transitions are more evident.

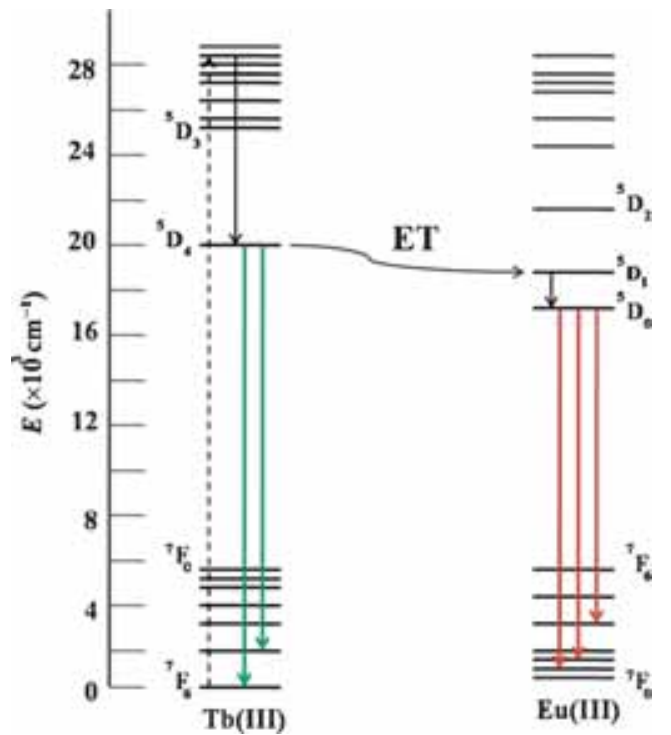

Figure 11. Energy level diagram showing energy transfer between $\mathrm{Tb}^{3+}$ and $\mathrm{Eu}^{3+}$ ion.

${ }^{7} \mathrm{~F}_{0} \rightarrow{ }^{5} \mathrm{H}_{6}(\mathrm{Eu}) ; 283 \mathrm{~nm}:{ }^{7} \mathrm{~F}_{6} \rightarrow{ }^{5} \mathrm{I}_{6}(\mathrm{~Tb}) ; 339 \mathrm{~nm}:$ ${ }^{7} \mathrm{~F}_{6} \rightarrow{ }^{5} \mathrm{G}_{2}(\mathrm{~Tb}) ; 377 \mathrm{~nm}:{ }^{7} \mathrm{~F}_{0} \rightarrow{ }^{5} \mathrm{G}_{2}(\mathrm{Eu})$; and $393 \mathrm{~nm}:$ ${ }^{7} \mathrm{~F}_{0} \rightarrow{ }^{5} \mathrm{~L}_{6}(\mathrm{Eu})$. When excited at $377 \mathrm{~nm}$, the corresponding emission spectrum comprises emission lines originating from both $\mathrm{Tb}^{3+}$ and $\mathrm{Eu}^{3+}$ ions. These lines are assigned at $490 \mathrm{~nm}:{ }^{5} \mathrm{D}_{4} \rightarrow{ }^{7} \mathrm{~F}_{6}(\mathrm{~Tb}) ; 545 \mathrm{~nm}:{ }^{5} \mathrm{D}_{4} \rightarrow{ }^{7} \mathrm{~F}_{5}(\mathrm{~Tb}) ; 592 \mathrm{~nm}:$ ${ }^{5} \mathrm{D}_{0} \rightarrow{ }^{7} \mathrm{~F}_{1}(\mathrm{Eu}) ; 615 \mathrm{~nm}:{ }^{5} \mathrm{D}_{0} \rightarrow{ }^{7} \mathrm{~F}_{2}(\mathrm{Eu})$; and $695 \mathrm{~nm}$ : ${ }^{5} \mathrm{D}_{0} \rightarrow{ }^{7} \mathrm{~F}_{4}(\mathrm{Eu})$. Emission spectrum shows only two emission lines with diminished intensity (out of characteristic four lines) of $\mathrm{Tb}^{3+}$ and only three emission lines with moderate intensity (out of characteristic four lines) of $\mathrm{Eu}^{3+}$. Upon excitation at $393 \mathrm{~nm}$, only emission lines originating from $\mathrm{Eu}^{3+}$ ion appear, whereas emission from $\mathrm{Tb}^{3+}$ is completely quenched. Figure 10a shows emission spectra of $\mathrm{Tb}^{3+}$-doped $\mathrm{NaLaF}_{4}$ and $\mathrm{Eu}^{3+} / \mathrm{Tb}^{3+}$ co-doped $\mathrm{NaLaF}_{4}$ nanoparticles when excited at $377 \mathrm{~nm}$. It is seen that characteristic emission from $\mathrm{Tb}^{3+}$ gets significantly quenched in $\mathrm{Tb}^{3+} / \mathrm{Eu}^{3+}$
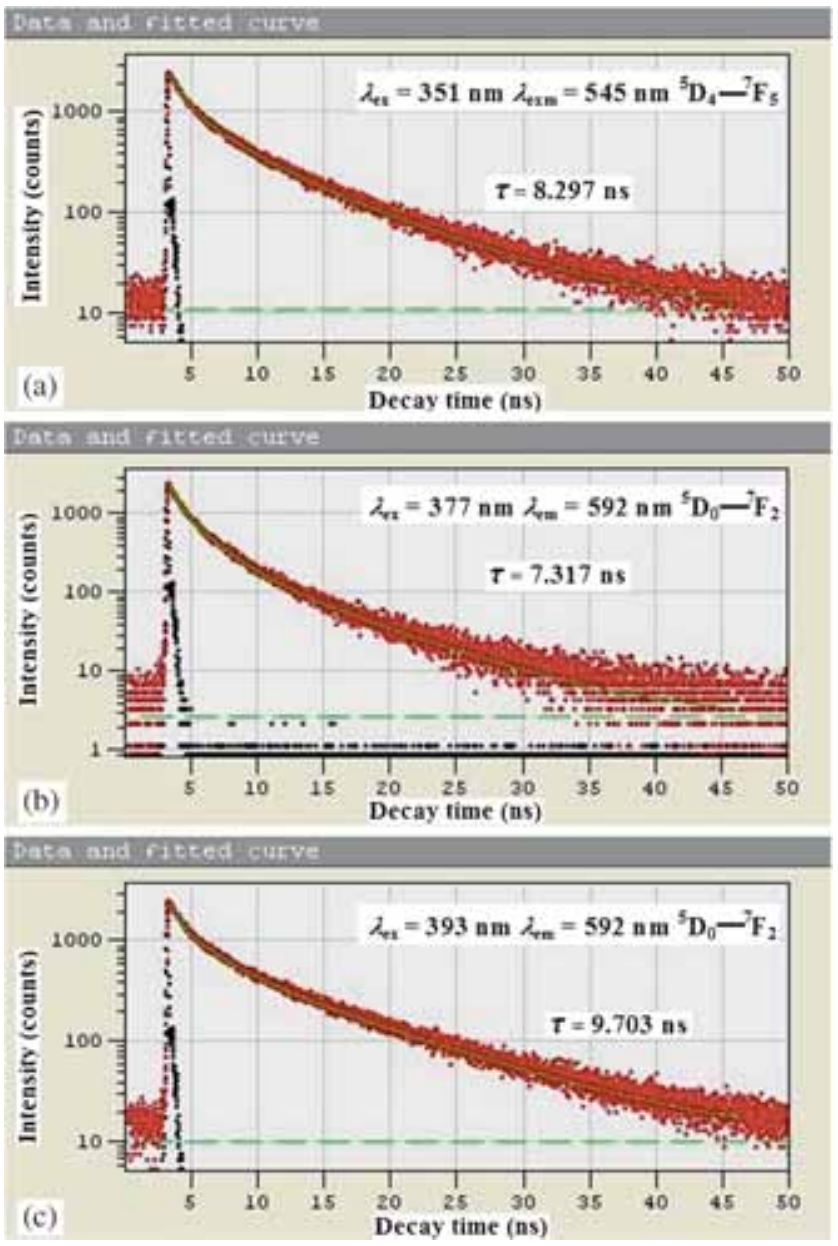

Figure 12. Decay curves of (a) $\mathrm{Tb}^{3+}$ in $\mathrm{NaLaF}_{4}: \mathrm{Tb}^{3+}$, (b) $\mathrm{Eu}^{3+}$ in $\mathrm{NaLaF}_{4}: \mathrm{Eu}^{3+}$ and (c) $\mathrm{Eu}^{3+}$ in $\mathrm{NaLaF}_{4}: \mathrm{Eu}^{3+} / \mathrm{Tb}^{3+}$ nanoparticles.

co-doped $\mathrm{NaLaF}_{4}$ nanoparticles as compared to $\mathrm{Tb}^{3+}$-doped nanoparticles. This suppression in intensity of $\mathrm{Tb}^{3+}$ emission lines is accompanied by concomitant enhancement in intensity of $\mathrm{Eu}^{3+}$ emission lines in $\mathrm{Eu}^{3+} / \mathrm{Tb}^{3+}$ co-doped 


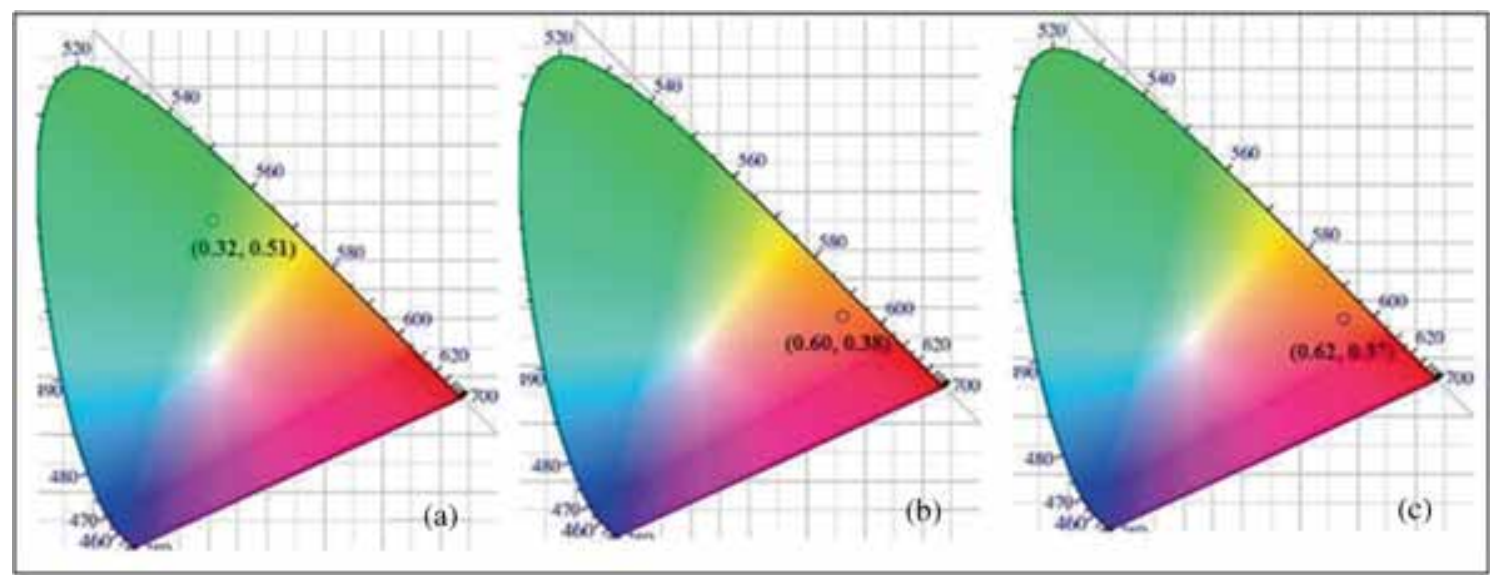

Figure 13. CIE chromatogram for $(\mathbf{a}) \mathrm{NaLaF}_{4}: \mathrm{Tb}^{3+}$, (b) $\mathrm{NaLaF}_{4}: \mathrm{Eu}^{3+}$ and (c) $\mathrm{NaLaF}_{4}: \mathrm{Eu}^{3+} / \mathrm{Tb}^{3+}$ nanoparticles.

$\mathrm{NaLaF}_{4}$ nanoparticles. This is further confirmed by comparison of intensity of emission lines in $\mathrm{Eu}^{3+}$-doped $\mathrm{NaLaF}_{4}$ and $\mathrm{Eu}^{3+} / \mathrm{Tb}^{3+}$ co-doped $\mathrm{NaLaF}_{4}$ nanoparticles (figure $10 \mathrm{~b}$ ). All these experimental observations indicate energy transfer from $\mathrm{Tb}^{3+}$ to $\mathrm{Eu}^{3+}$ when excited at $377 \mathrm{~nm}$. Thus, $\mathrm{Eu}^{3+} / \mathrm{Tb}^{3+}$ co-doped $\mathrm{NaLaF}_{4}$ nanoparticles are much better phosphors than $\mathrm{Eu}^{3+}$-doped $\mathrm{NaLaF}_{4}$ nanoparticles, but less phosphor than $\mathrm{Tb}^{3+}$-doped $\mathrm{NaLaF}_{4}$ nanoparticles. The schematic diagram for non-radiative energy transfer process from $\mathrm{Tb}^{3+}$ to $\mathrm{Eu}^{3+}$ is shown in figure 11. Thus, energy transfer from one lanthanide ion can be used to enhance the luminescence of the other lanthanide ion.

The luminescence decay curves of $\mathrm{Tb}^{3+}$ in $\mathrm{NaLaF}_{4}: \mathrm{Tb}^{3+}$ (figure 12a), $\mathrm{Eu}^{3+}$ in $\mathrm{NaLaF}_{4}: \mathrm{Eu}^{3+}$ (figure 12b) and $\mathrm{NaLaF}_{4}$ $: \mathrm{Eu}^{3+} / \mathrm{Tb}^{3+}$ (figure 12c) can be well fitted into a single exponential function as $I_{(\mathrm{t})}=I_{0} \exp (-t / \tau)\left(I_{0}\right.$ is the initial emission intensity at $t=0$ and $\tau$ the lifetime of the emission centre). The lifetime of $\mathrm{Tb}^{3+}$ in $\mathrm{NaLaF}_{4}: \mathrm{Tb}^{3+}$ nanoparticles is $8.297 \mathrm{~ns}$ and that of $\mathrm{Eu}^{3+}$ in $\mathrm{NaLaF}_{4}: \mathrm{Eu}^{3+}$ and $\mathrm{NaLaF}_{4}: \mathrm{Eu}^{3+} / \mathrm{Tb}^{3+}$ nanoparticles are 7.317 and $9.703 \mathrm{~ns}$, respectively, as shown in figure $13 \mathrm{a}-\mathrm{c}$. Increase in the value of luminescence lifetime for $\mathrm{Eu}^{3+} / \mathrm{Tb}^{3+}$ co-doped $\mathrm{NaLaF}_{4}$ : $\mathrm{Eu}^{3+} / \mathrm{Tb}^{3+}$ nanoparticles proves the highly efficient energy transfer process occurring from $\mathrm{Tb}^{3+}$ to $\mathrm{Eu}^{3+}$ relative to that in $\mathrm{NaLaF}_{4}: \mathrm{Eu}^{3+}$ and $\mathrm{NaLaF}_{4}: \mathrm{Tb}^{3+}$ nanoparticles. The emission intensity and radiative life time are sensitive to crystal structure and hexagonal phase has been found to give intense emission with longer life time [43].

\subsection{Commission International De I'Eclairage (CIE) coordinates}

The chromaticity coordinates of doped-NaLaF 4 nanoparticles have been calculated from the emission spectra by using the CIE system. Figure 13a shows the CIE chromaticity diagram for $\mathrm{NaLaF}_{4}: \mathrm{Tb}^{3+}$ nanoparticles upon excitation at 351 $\mathrm{nm}$, whereas figure $13 \mathrm{~b}$ and $\mathrm{c}$ shows the same for $\mathrm{NaLaF}_{4}$ $: \mathrm{Eu}^{3+}$ and $\mathrm{NaLaF}_{4}: \mathrm{Eu}^{3+} / \mathrm{Tb}^{3+}$ nanoparticles, respectively, upon excitation at $377 \mathrm{~nm}$. The CIE coordinate is found
$(0.32,0.51)$ for $\mathrm{Tb}^{3+}$-doped $\mathrm{NaLaF}_{4}$ nanoparticles emitting green light, whereas it is $(0.60,0.38)$ and $(0.62,0.37)$ for $\mathrm{NaLaF}_{4}: \mathrm{Eu}^{3+}$ and $\mathrm{NaLaF}_{4}: \mathrm{Eu}^{3+} / \mathrm{Tb}^{3+}$ nanoparticles, respectively, emitting red light. These results indicate very favourable luminescent features of these nanoparticles.

\section{Conclusion}

Hexagonal phase undoped and doped-NaLaF 4 submicron rods have been synthesized via a simple hydrothermal route by employing $\mathrm{NH}_{4} \mathrm{BF}_{4}$ as fluoride source and citric acid as the structure-directing agent. The phase and morphology evolution process as well as the formation mechanism were discussed. XRPD and DLS analyses confirmed the size of particles in the nanometric range. PL studies suggest a general route for the development of highly efficient luminescent DC phosphors in a broad colour range, which have potential application in diverse fields. Purity in colour of nanoparticles is confirmed by means of colour coordinates. This synthetic procedure is facile, environmentally friendly and may be extended to prepare other materials with submicron morphology.

\section{Acknowledgements}

We would like to acknowledge Indian Institute of Technology Roorkee and Indian Institute of Technology Guwahati for their technical support. We also thank School of Physics, Shri Mata Vaishno Devi University (SMVDU) for photoluminescence studies.

\section{References}

[1] Huang X, Han S, Huang W and Liu X 2013 Chem. Soc. Rev. 42173

[2] Bunzli J C G, Comby S, Chauvin A S and Vandevyver C D B 2007 J. Rare Earths 25257 
[3] Mahalingam V, Mangiarini F, Vetrone F, Venkatramu V, Bettinelli M, Speghini A et al 2008 J. Phys. Chem. 11217745

[4] Kumar G A, Chen C W, Ballato J and Riman R E 2007 J. Mater. Chem. 191523

[5] Liu H, Wang H, Zang X and Chen D 2009 J. Mater. Chem. 19 489

[6] Evanics F, Diamente P R, van Veggel F C, Stanisz G J and Prosser R S 2006 J. Mater. Chem. 82499

[7] Kumar R, Nyk M, Ohulchanskyy T Y, Flask C A and Prasad P N 2009 Adv. Funct. Mater. 19853

[8] Auzel F 2004 Chem. Rev. 104139

[9] Downing E, Hesselink L, Ralston J and Macfarlane R 1996 Science 2731185

[10] Jacinto C, Vermelho M, Gouveia E, de Araujo M, Udo P, Astrath N et al 2007 Appl. Phys. Lett. 91071102

[11] van der Ende B M, Aarts L and Meijerink A 2009 Phys. Chem. Chem. Phys. 1111081

[12] Nyk M, Kumar R, Ohulchanskyy T Y, Bergy E J and Prasad P N 2008 Nano Lett. 83834

[13] Qin X, Yokomori T and Ju Y G 2007 Appl. Phys. Lett. 90 073104

[14] Shan J S and Ju Y G 2007 Appl. Phys. Lett. 91123103

[15] Kramer K W, Biner D, Frei G, Gudel H U, Hehlen M P and Luthi S R 2004 Chem. Mater. 161244

[16] Li C, Yang J, Yang P, Lian H and Lin J 2008 Chem. Mater. 20 4317

[17] Xia Z G and Du P 2010 J. Mater. Res. 252035

[18] Zeng S J, Ren G Z, Xu C F and Yang Q B 2011 Cryst. Eng. Comm. 134276

[19] Ghosh P and Patra A 2008 J. Phys. Chem. 11219283

[20] Ghosh P and Patra A 2008 J. Phys. Chem. 1123223

[21] Ghosh P, Kar A and Patra A K 2010 J. Phys. Chem. C 114715

[22] Chen G Y, Ohulchanskyy T Y, Kachynski A, Agren H and Prasad P N 2011 AC Nano 54981

[23] Teng X, Zhu Y, Wei W, Wang S, Huang J, Naccache R et al 2012 J. Am. Chem. Soc. 1348340
[24] Shang M, Li G, Kang X, Yang D, Geng D, Peng C et al 2012 Dalton Trans. 415571

[25] Shang M M, Geng D L, Kang X J, Yang D M, Zhang Y and Lin J 2012 Inorg. Chem. 5111106

[26] He M, Huang P, Zhang C L, Hu H Y, Bao C C, Gao G et al 2011 Adv. Funct. Mater. 214470

[27] Zhou J, Zhu X J, Chen M, Sun Y and Li F Y 2012 Biomaterials 336201

[28] Li F, Li C, Liu X, Chen Y, Bai T, Wang L et al 2012 Chem. Eur. J. 1811641

[29] Dawer A L, Shishodia P K, Chouhan J, Kumar G and Mathur A 1990 Mater. Sci. Lett. 9547

[30] Tian Z R, Voigt J A, Liu J, Mckenzie B, Mcdermott M J, Rodriguez M A et al 2003 Nat. Mater. 2821

[31] Sun Y J, Chen Y, Tian L J, Yu Y, Kong X G, Zhao J W et al 2007 Nanotechnology 18275609

[32] Whitesides G M and Grzybowski B 2002 Science 2952418

[33] Wang Z L, Hao J H and Chan H L W 2010 Cryst. Eng. Comm. 121373

[34] Zhao J W, Sun Y J, Kong X G, Tian L J, Wang Y, Tu L P et al 2008 J. Phys. Chem. 11215666

[35] Wang F, Han Y, Lim C, Lu Y, Wang J, Xu J et al 2010 Nature 4631061

[36] Eliseevaa S V and Bunzli J C G 2010 Chem. Soc. Rev. 39189

[37] Bunzli J C G and Piguet C 2005 Chem. Soc. Rev. 341048

[38] Guangshun Y, Lee W B and Chow G M 2007 J. Nanosci. Nanotechnol. 72790

[39] Binnemans K 2009 Chem. Soc. Rev. 1094283

[40] Gaft M H, Reisfeld R and Panczer G 2005 Luminescence spectroscopy of minerals and materials, 2nd edn (Berlin, Heidelberg: Springer)

[41] Kirby A F, Foster D and Richardson F S 1983 Chem. Phys. Lett. 95507

[42] Kirby A F and Richardson F S 1983 J. Phys. Chem. 872544

[43] Ghosh P and Patra A 2008 J. Phys. Chem. C 112 19283; 112 3223 